\title{
Multi-band Annular Ring Microstrip Antenna with Defected Ground Structure for Wireless Communication
}

\author{
Puneet Khanna \\ Electronics and \\ Communication Engineering, \\ IFTM University, Moradabad, \\ India
}

\author{
Kshitij Shinghal \\ Electronics and \\ Communication Engineering, \\ M.I.T Moradabad, India
}

\author{
Arun Kumar \\ Electronics and \\ Communication Engineering, \\ IFTM University, Moradabad, \\ India
}

\begin{abstract}
An annular ring microstrip antenna (ARMSA) with a defected ground structure for multi-band operation is being proposed. Defected ground structure is produced by integrating a circular slot in the ground plane having different centre with the annular ring radiator patch. Microstrip line feed is used to excite the annular ring patch antenna placed on an FR4 substrate (dielectric constant $\varepsilon_{\mathrm{r}}=4$ ). Results of the proposed antenna are carried out using Ansoft HFSS simulation software, and compared with the measured results, which shows good agreement. It is observed that the proposed antenna shows four bands at $f_{1}=2.92 \mathrm{GHz}, f_{2}=5.64 \mathrm{GHz}, f_{3}=$ $8.21 \mathrm{GHz}$, and $f_{4}=10.53 \mathrm{GHz}$ with an impedance bandwidth of $70 \%, 50 \%, 20 \%$ and $10 \%$ respectively. The proposed antenna is suitable for $\mathrm{S}, \mathrm{C}$ and $\mathrm{X}$ band wireless communication system.
\end{abstract}

\section{Keywords}

Multi-band, Annular Ring Microstrip Antenna, Defected Ground Structure, Microstrip line feed.

\section{INTRODUCTION}

In today's modern era there is constant growth and requirement of development in the field of multi-band communication system. The growth and developments in these technologies has lead to a new trend in wireless communication, networking and satellite applications [1, 2]. There are few essential requirements while designing an antenna. The parameters which should be considered before designing any antenna are its size, cost, ease of fabrication. The limitations of the conventional microstrip antenna are its narrow bandwidth, efficiency, and size $[3,4,5]$. There is a tradeoff between among parameters for example if we optimize one parameter such as size (less than $\lambda / 2$ ) this may lead to decrease in bandwidth, gain, radiation resistance. Annular ring shape is a very promising solution for these problems [6,7]. In the recent years, several shapes have been proposed by antenna researchers to obtain multi-band, wideband and miniaturization of microstrip patch antenna. In addition of different shapes, diverse methods are also used for obtaining dual frequency and good efficiency such as: stacked antenna, cutting slots in the radiating patch or in the ground plane, or by changing the dielectric constant of the substrate [8-12].

These methods will give the wideband, dual band, but not multi bands [13-17]. One of the suitable methods is defecting the ground structure having a different centre with annular ring patch for obtaining multiple frequency bands.

The objective of this work is to design an ARMSA with defected ground structure feed by microstrip line so that, it can operate on multiple frequency bands i.e. $2.92 \mathrm{GHz}, 5.64$ $\mathrm{GHz}, 8.21 \mathrm{GHz}$, and $10.53 \mathrm{GHz}$. Thus, a new design is being investigated along with the simulation and measurements obtained.

The next section deals with multiband antenna design technique used for wireless communication, in detail. Section 3 covers experimental results and its discussion. Section 4 concludes all the discussion made earlier.

\section{ANTENNA DESIGN CONSIDERATION}

The design of the ring shape proposed antenna has been shown in figure 1 (a), (b). The proposed antenna consists of a defected ground structure and a circular radiating patch connected to a microstrip feed line. The antenna was fabricated and printed on a FR-4 substrate having relative permittivity $\varepsilon_{\mathrm{r}}=4.4$, thickness $h=1.6 \mathrm{~mm}$ and loss tangent $\tan \delta=0.024$. The overall size of the antenna is $35 \times 30 \times 1.6$ $\mathrm{mm}^{3}$. The simulation software High-Frequency Structure Simulator (HFSS) [18] is used to optimize the dimensions of the proposed design on the basis of best performance. The width of the microstrip feed line is fixed at $1.5 \mathrm{~mm}$ to achieve $50 \Omega$ characteristic impedance. An annular patch having outer radius, $R_{1}=11 \mathrm{~mm}$ and inner radius $R_{2}=6 \mathrm{~mm}$ is taken having centre position $C_{1}=(0,0)$ and provided a feed of width, $W_{\mathrm{f}}=1.5 \mathrm{~mm}$ with an outer radius of annular ring, a circle of radius $R_{3}=12 \mathrm{~mm}$ with a circle centre position at $C_{2}$ $=(-3.5,0)$ is cut in ground plane to make defected ground plane. For obtaining multi bands and better return loss along with an efficiency of $88 \%$, following parameters of the proposed antenna have taken which are shown in table 1 as given below:

\section{Table 1 Proposed antenna design parameters}

\begin{tabular}{|l|c|c|c|c|c|}
\hline Parameters & $L_{1}$ & $W_{1}$ & $R_{1}$ & $R_{2}$ & $R_{3}$ \\
\hline Units (mm) & 35 & 30 & 11 & 06 & 12 \\
\hline Parameters & $W_{\mathrm{f}}$ & $L_{\mathrm{f}}$ & $C_{1}$ & $C_{2}$ & \\
\hline Units (mm) & 1.5 & 7.5 & 0,0 & $-3.5,0$ & \\
\hline
\end{tabular}




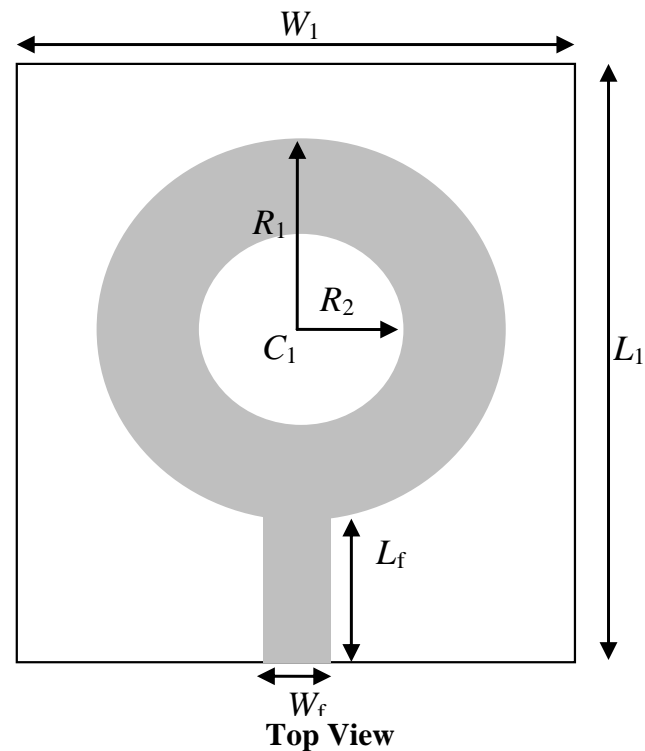

(a)

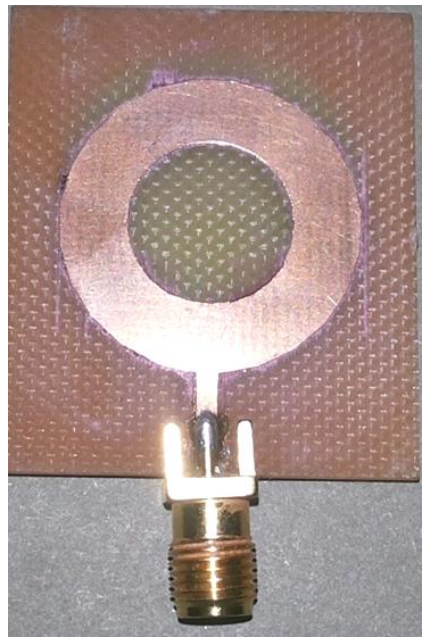

Top View

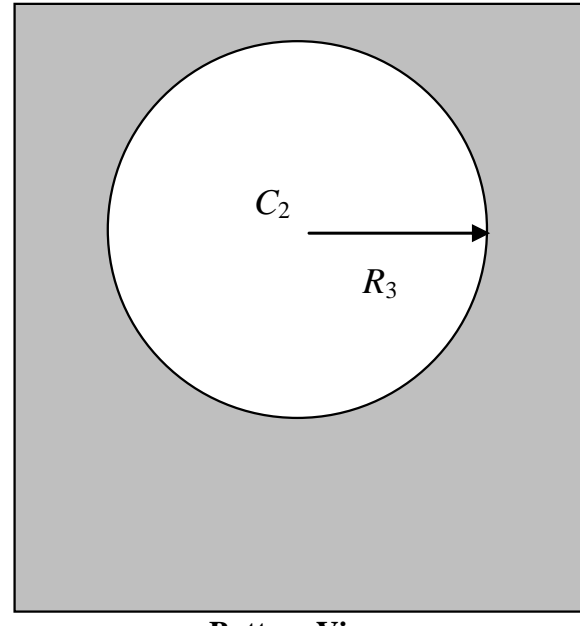

Bottom View

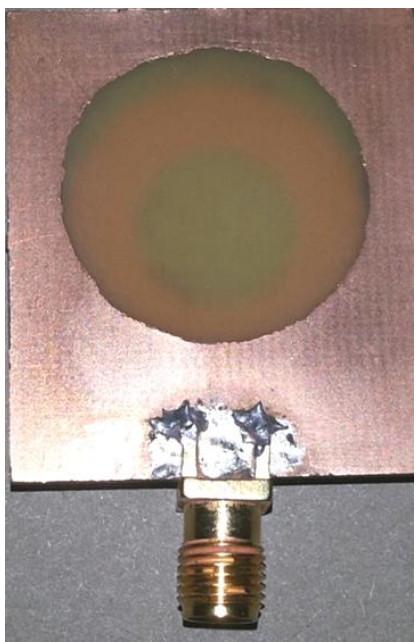

Bottom View

(b)

Figure 1 (a) proposed antenna geometry and (b) image of fabricated antenna (Drawing is not in scale)

\section{DISCUSSION OF RESULTS}

\subsection{Variation of Patch Parameters}

Figure 2 shows, the simulated return loss of the proposed antenna with outer radius $R_{1}$ varies from 10 to $12 \mathrm{~mm}$. Bandwidth for return loss $(<10 \mathrm{~dB})$ for the above said antenna decreases as the radius $R_{1}$ increases from $11 \mathrm{~mm}$ to 12 $\mathrm{mm}$. Therefore, it is decided to take $R_{1}=11 \mathrm{~mm}$ as the results of the multiband ARMSA covers four bands.

Further, Figure 3 shows the simulated results of the proposed antenna with inner radius $R_{2}$ varies from $5 \mathrm{~mm}$ to $7 \mathrm{~mm}$. It was observed that the return loss of the antenna decreases as the value of radius increases. Therefore we took $R_{2}=6 \mathrm{~mm}$ as the optimum radius, to get multi-bands from $2.92 \mathrm{GHz}$ to $10.53 \mathrm{GHz}$ frequency range.

\subsection{Variation of Ground Parameters}

Figure 4, shows the simulated results of the proposed multiband ARMSA showing the effects of slot in the ground plane. For the solid ground plane (without any slot), the return loss condition appears to be worse over the entire frequency band. As for the case of ground plane with radius $R_{3}=11 \mathrm{~mm}$ the matching condition still not acceptable at $2.92 \mathrm{GHz}$ and $5.64 \mathrm{GHz}$. However, the four resonant bands appear around $2.92 \mathrm{GHz}, 5.64 \mathrm{GHz}, 8.21 \mathrm{GHz}$, and $10.53 \mathrm{GHz}$. The similar case appears when the radius $R_{3}=13 \mathrm{~mm}$ is taken. Therefore, it is decided that the ground plane with radius $R_{3}=12 \mathrm{~mm}$ is taken which improves the results for the entire frequency band. 




Figure 2 Variation in return loss with frequency for different radius $\left(R_{1}\right)$, other parameters are same as listed in Table 1.

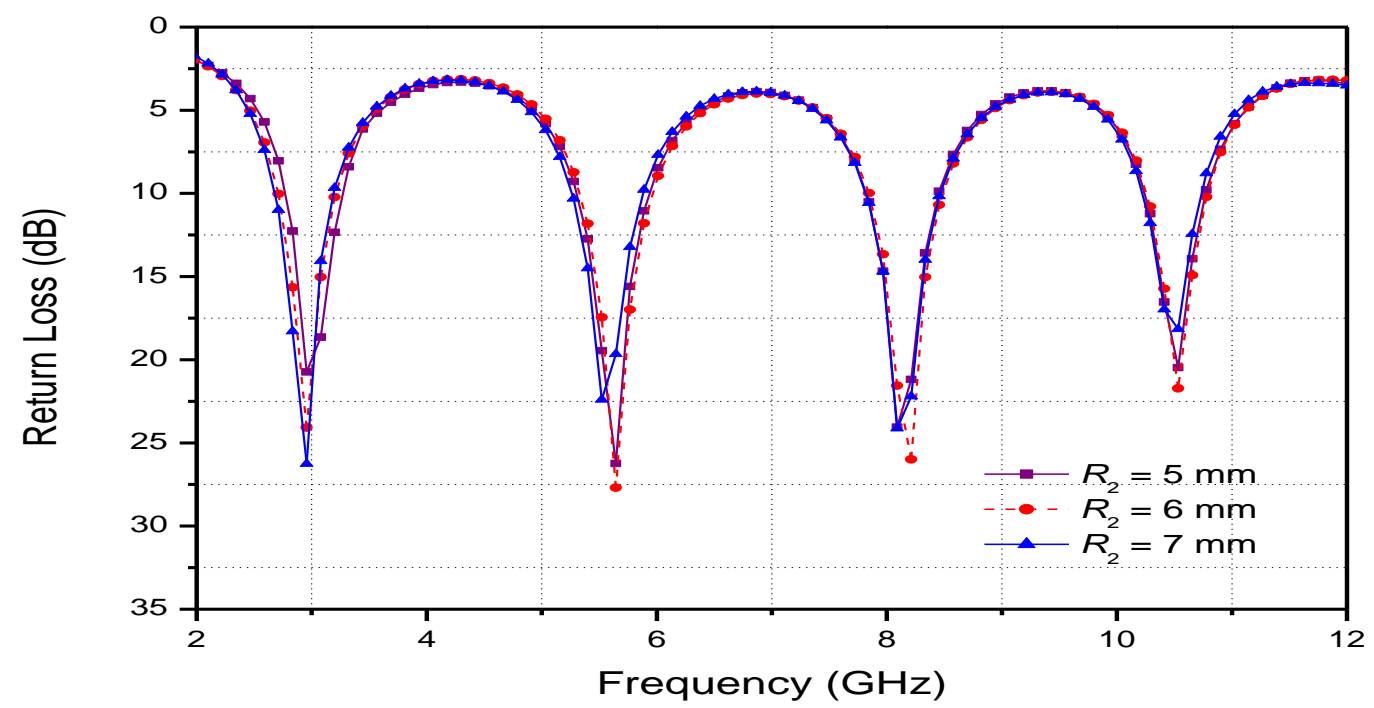

Figure 3 Variation in return loss with frequency for different radius $\left(R_{2}\right)$, other parameters are same as listed in Table 1.

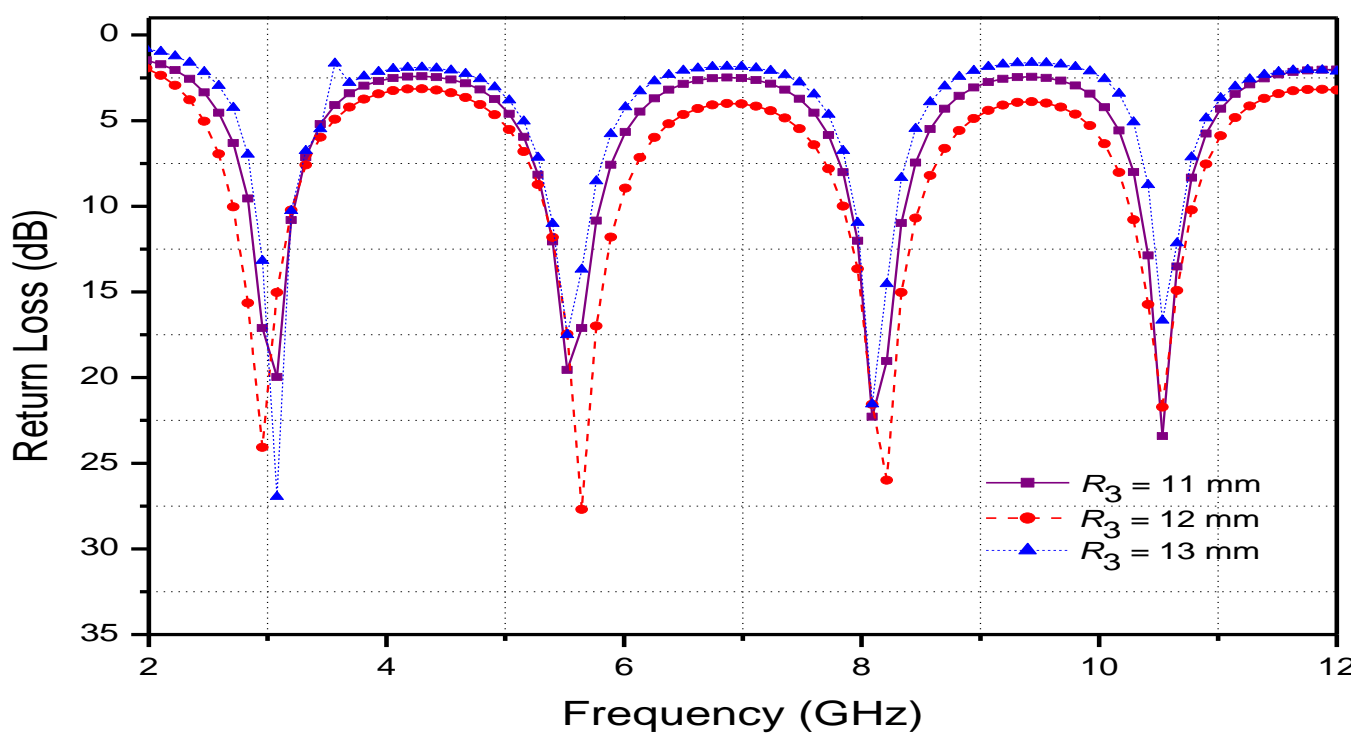

Figure 4 Variation in return loss with frequency for different radius $\left(R_{3}\right)$, other parameters are same as listed in Table 1. 


\subsection{Variation of Microstrip Feed Parameters}

Figure 5, shows the simulated results of the proposed multiband ARMSA with width of microstrip feed $W_{\mathrm{f}}$ varies from $1.0 \mathrm{~mm}$ to $2.0 \mathrm{~mm}$. It was observed that the antenna shows better return loss at $W_{\mathrm{f}}=1.5 \mathrm{~mm}$. Therefore it is decided to take $W_{\mathrm{f}}=1.5 \mathrm{~mm}$ as the optimum width for obtaining multi-bands from $2.92 \mathrm{GHz}$ to $10.53 \mathrm{GHz}$ frequency range with better return loss. While Figure 6, shows the simulated results of the proposed multiband ARMSA with length of microstrip feed $L_{\mathrm{f}}$ varies from $7.3 \mathrm{~mm}$ to $7.7 \mathrm{~mm}$. It was observed that the bandwidth is almost same in all the four bands, but the return loss varies. Therefore it is decided to take $L_{\mathrm{f}}=7.5 \mathrm{~mm}$ as the optimum length to obtain better return loss with multi-bands.



Figure 5 Variation in return loss with frequency for feed width $\left(W_{f}\right)$, other parameters are same as listed in Table 1.

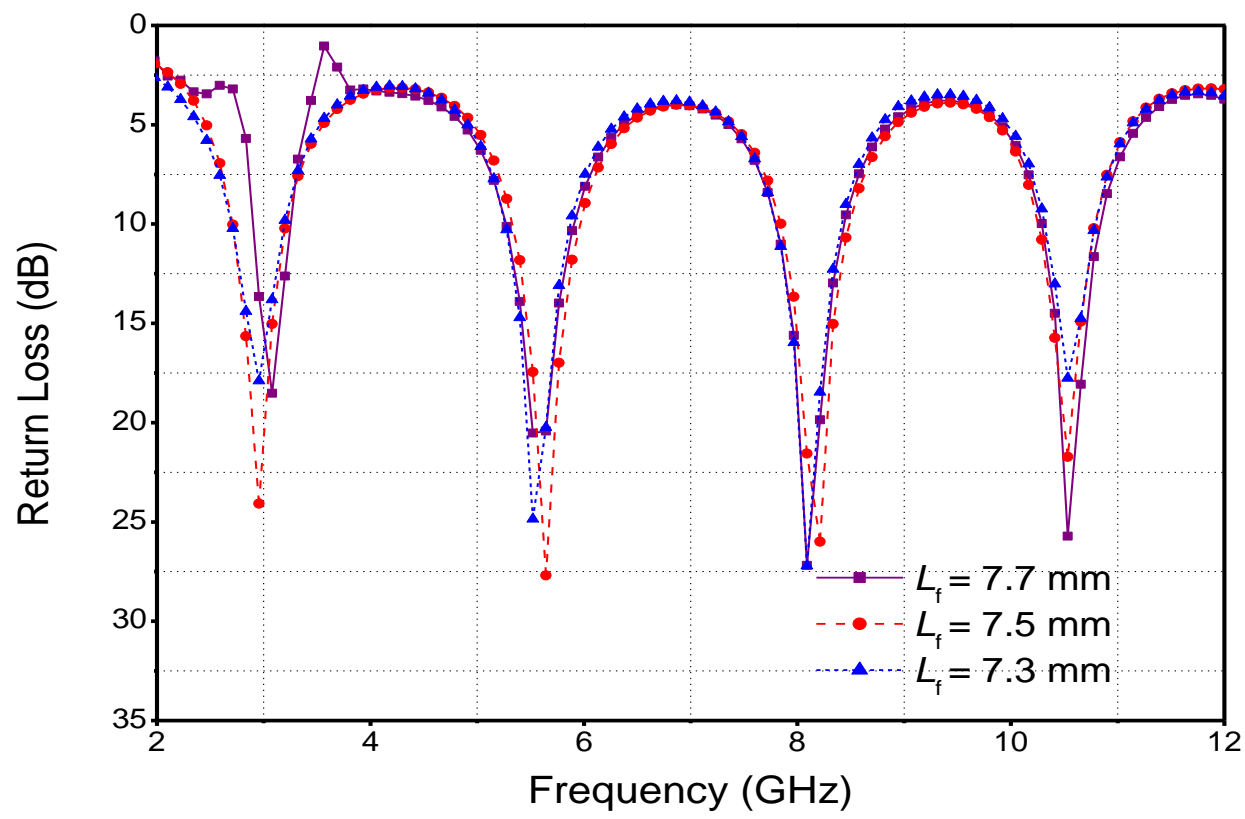

Figure 6 Variation in return loss with frequency for feed length $\left(L_{\mathrm{f}}\right)$, other parameters are same as listed in Table 1.

An Agilent 8757E scalar network analyzer was used to measure the performance of the proposed antenna such as return loss. There is a balanced agreement in measured and simulated return loss curves of the proposed multiband ARMSA that is shown in figure 7. The small difference between measured and simulated results is due to the effect of SMA (Sub Miniature version A) connector soldering and fabrication. The designed antenna shows multiband between $2.92 \mathrm{GHz}$ to $10.53 \mathrm{GHz}$ frequency range.
Figures 8 (a) to 8 (d) shows the measured and simulated far field radiation patterns in the $\mathrm{H}$ and $\mathrm{E}$ planes at frequencies $2.92 \mathrm{GHz}, 5.64 \mathrm{GHz}, 8.21 \mathrm{GHz}$, and $10.53 \mathrm{GHz}$. It has been searched out that the multiband ARMSA has good radiation patterns at all frequencies in both the planes. This pattern works on $\mathrm{S}, \mathrm{C}$ and $\mathrm{X}$ band and is most suitable for wireless communication systems 


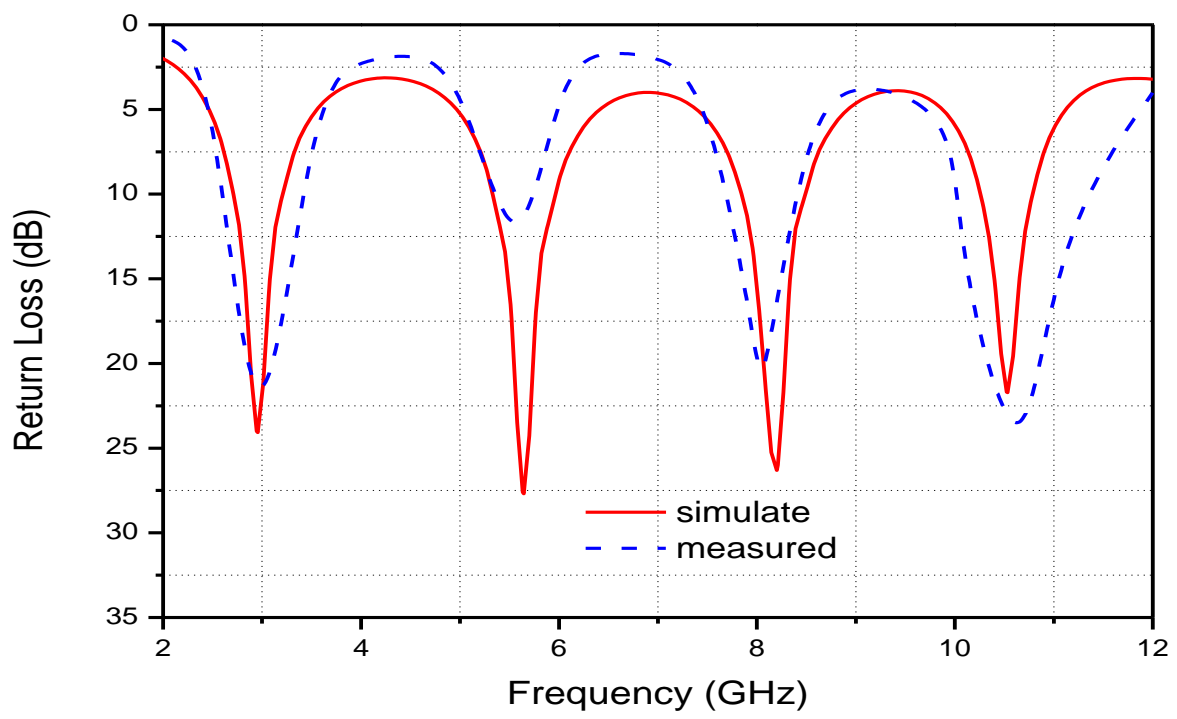

Figure 7 Simulated and Measured Return Loss of proposed antenna.
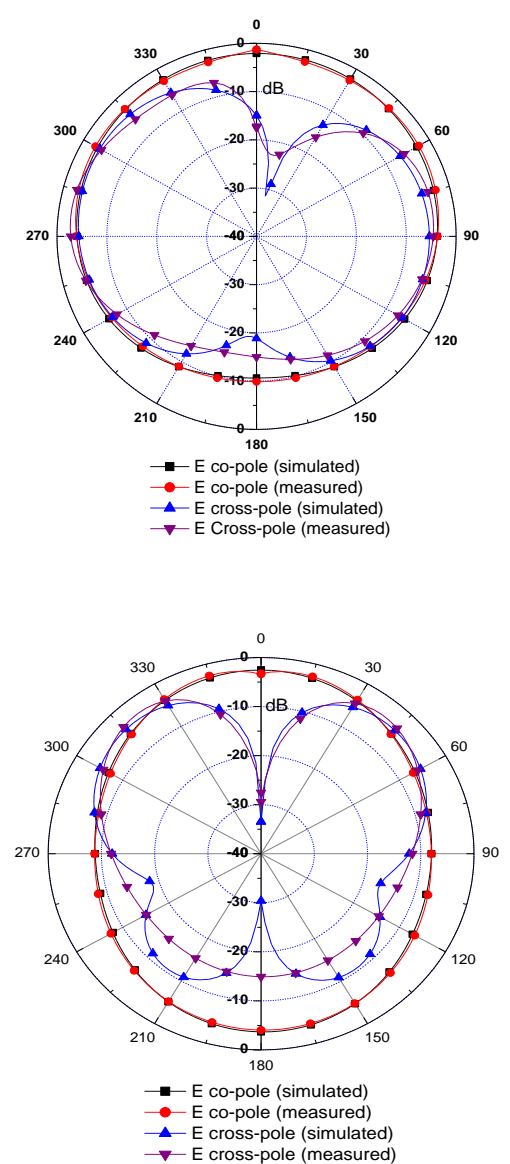



(a)

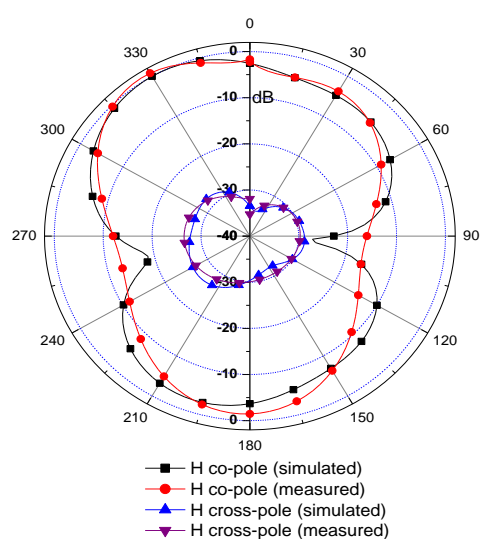

(b) 

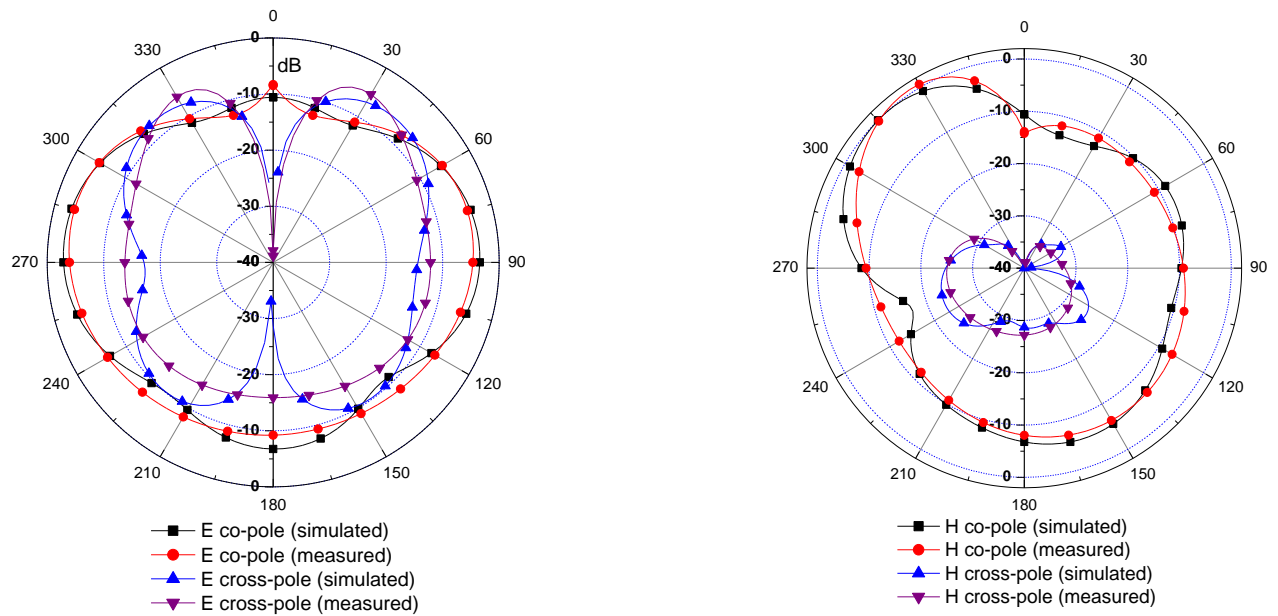

(c)
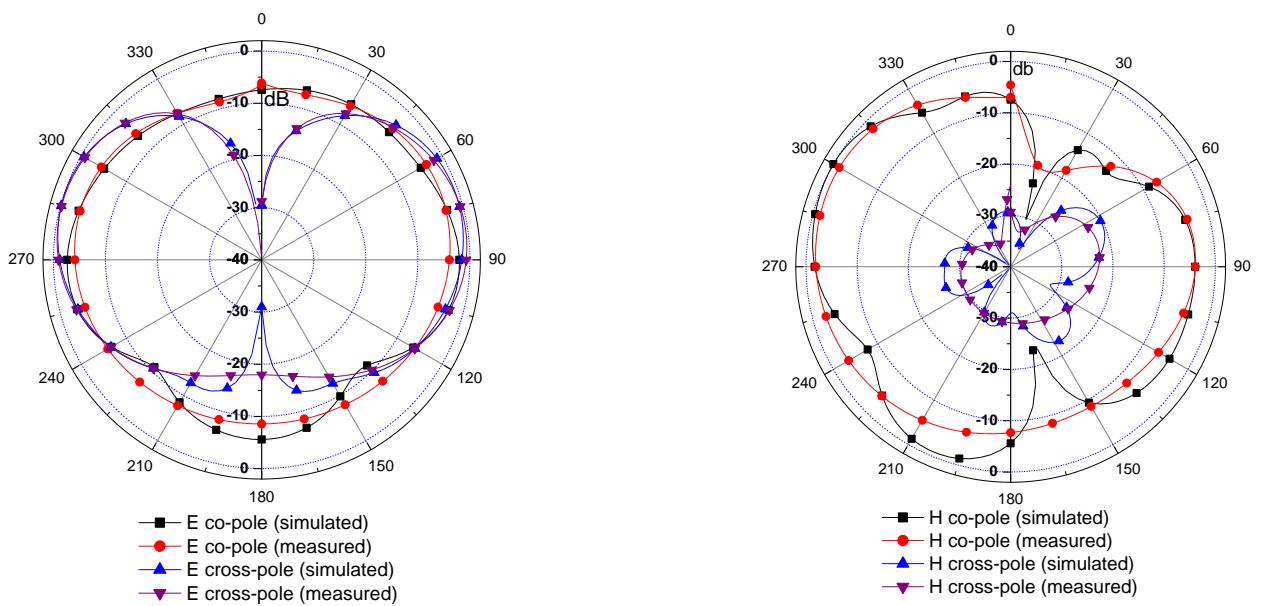

(d)

Figure 8 Measured and simulated radiation patterns of various resonance frequencies for the proposed Multiband ARMSA at (a) $2.92 \mathrm{GHz}$ (b) $5.64 \mathrm{GHz}$ (c) $8.21 \mathrm{GHz}$ (d) $10.53 \mathrm{GHz}$

\section{CONCLUSION}

The proposed ARMSA with defected ground structure for multiband operation has been designed, simulated and fabricated. The effect of defected ground structure on multiband has been studied using HFSS simulation software. The four different frequencies range $2.92 \mathrm{GHz}, 5.64 \mathrm{GHz}$, $8.21 \mathrm{GHz}$, and $10.53 \mathrm{GHz}$ generally works on $\mathrm{S}, \mathrm{C}$ and $\mathrm{X}$ band and it has been found out most suitable for wireless communication systems. The antenna has an efficiency of $88 \%$ and omnidirectional radiation patterns over the entire frequency band. The antenna has a bandwidth of over $15.76 \%$, $10.78 \%, 7.74 \%$, and $5.5 \%$ in the frequency ranges from 2.7325 to $3.2 \mathrm{GHz}, 5.345$ to $5.95 \mathrm{GHz}, 7.8475$ to $8.48 \mathrm{GHz}$, and 10.193 to $10.78 \mathrm{GHz}$. The future scope of the proposed antenna includes the measurement of gain, time delay and mathematical analysis.

\section{REFERENCES}

[1] T.G. Ma, S.K. Jeng, "Planar miniature tapered-slot-fed annular slot antennas for ultra-wideband radios", IEEE Trans Antennas Propagation vol. 53, pp. 1194-1202, 2005.

[2] C Y Huang, W C Hsia, "Planar elliptical antenna for ultra wideband communications", Electronics Letters, vol. 41, pp. 296-297, 2005.
[3] J Liang, CC Chiau, XD Chen, CG Parini, "Study of a printed circular disc monopole antenna for UWB systems", IEEE Transactions Antennas Propagation, vol. 53, pp. 3500-3504, 2005.

[4] R. Garg, P. Bhartia, I.Bahl and A. Ittipiboon, Microstrip Antenna Design Handbook, Artech House, Boston, Mass, USA, 2001.

[5] A. K. Gautam, R. Chandel, B. K. Kanaujia, "A CPW-fed hexagonal shape monopole like UWB antenna", Microwave Optical Technology Letters, vol. 55, pp. 2582-2587, 2013.

[6] P. H. Rao, V.F. Fusco, R. Cahill, "Linearly polarized radial stub fed high performance wide-band slot antenna”, Electronics Letters, vol.37, pp. 335-337, 2001.

[7] Raj Kumar, K.K Sawant, "Design of CPW fed fourth iterative UWB fractal antenna”, International Journal of Microwave and Optical Technology, vol. 5, no. 6, pp. 320-327, November 2010.

[8] P Li, J Liang, X Chen, "Study of printed elliptical/circular slot antennas for ultra-wideband applications", IEEE Transactions Antenna Propagation, vol. 54, pp. 1670-1675, 2006. 
[9] M. J. Ammann and X. L. Bao, "Miniatured annular ring loaded patch antennas", IEEE Antennas and Propagation Society International Symposium, Honolulu, pp. 912915, 9-15 June 2007.

[10] J.T. Rayno, T.T.S. Hlaing, S.K. Sharma, "Novel multiband segmented dual-aperture-coupled annular ring microstrip patch for wireless router MIMO antenna system", IEEE, Antennas and Propagation Society International Symposium (APSURSI), Orlando, FL, pp. 368-369, 7-13 July 2013.

[11] P. Mythili, P. Cherian, S. Mridula, Binu Paul, “ Design of Compact Multiband Microstrip antenna", IEEE, India Conference (INDICON), Gujarat, pp. 1-4, 18-20 December, 2009.

[12] Jin-Sen Chen, "Dual Frequency Annular ring sot antenna fed by CPW feed and microstrip line feed", IEEE transactions on antennas and propagation, vol. 53, no. 1, pp. 569-571, January 2005.

[13] M.R. Khan, M.M. Morsy, M.Z. Khan, "Dual band antenna for wireless network (WLAN) applications", IEEE International Symposium on Antennas and Propagation (APSURSI), Spokane, WA, pp. 1397-1400, 3-8 July, 2011.

[14] Atta-Ur-Rahim, S. Ullah, M.Ilyas, M. Shoaib, "Design and analysis of compact and multi-band circular antennas", IEEE, International Conference on Open Source Systems and Technologies (ICOSST), Lahore, pp. 52-55, 18-20 December, 2014.

[15] Y.Y Sun, S.W. Cheung and T.I. Yuk, "Design of a very compact UWB monopole antenna with microstrip fed", Microwave and Optical Technology Letters, vol. 55, no. 9, pp. 2232-2236, September 2013.

[16] C.M. Wu, Y.L. Chen and W.C. Liu, "A compact ultra wideband slotted patch antenna for wireless USB dongle application”, IEEE Antennas Wireless Propagation Letter, pp. 596-599, November 2012.

[17] Yongseok Seo, Hyeonjin Lee and Yeongseog Lim, "Design of a circular ring monopole antenna with inverted T-strip line for dual band operation", Microwave and Optical Technology Letters, vol. 55, No. 9, pp. 21742177, September 2013.

[18] Ansoft, HFSS simulator version 14.0, Ansoft Corp., Pittsburgh, PA.

\section{AUTHOR PROFILE}

Puneet Khanna was born in Moradabad, U.P India on February 21, 1981. He received B.Tech degree in Electronics \& Inst. Engg. and M.Tech degree in Microwave Engineering from UPTU Lucknow, India in 2004 and 2011 respectively. He is currently working as Asstt. Professor in Deptt. of Electronics \& Communication Engineering at IFTM University, Moradabad. He is a student member of IEEE. His current research is in design and analysis of defected structure shaped microstrip antennas.

Kshitij Shinghal has 14 Years of experience in the field of academic and is actively involved in research \& development activities. He obtained his Masters (Digital Communication) in 2006 from UPTU, Lucknow and Ph.D. degree from Shobhit University. He started his career from MIT,

Moradabad. Presently he is working as an Associate Professor \& Head, Deptt of E\&C Engg., at MIT Moradabad. He has published number of papers in national journals, conferences and seminars. He has guided two Ph.D. \& more than six students of M. Tech, and guiding three M.Tech. theses. He is an active Member of various Professional Societies such as ISTE, IACSIT, IAENG etc.

Arun Kumar was born in Dehradun, India on May 11, 1946 $\mathrm{He}$ received the B.E degree in Electronics \& Comm. Engineering from Govt. Engineering College, Jabalpur, M.P He obtained his M.E and Ph. D. degree from University of Roorkee in 1973 and 1980 respectively. He is currently Professor at School of Engineering \& Technology, IFTM University, Moradabad. U.P Earlier he worked at Madan Mohan Malviya Engineering College, Gorakhpur as Professor and Head, Deptt. of Electronics \& Comm. Engineering. He also served at Yamoukh University, Irbid, Jordan as visiting professor. 